The authors conclude that the 4AT is a sensitive and specific test for postcardiotomy delirium detection. The sensitivity, however, was markedly reduced among the nurse-administered assessments $(58 \%$ vs $85 \%$ among the research assistant assessments). We wonder whether the results would differ if the instruction on administration, frequency and timing of assessments, and comparison to reference were standardized among all assessments, enabling more effective comparison of the data. If the sensitivity remained this low after addressing these factors, it would argue against the efficacy of the 4AT in the screening of patients postcardiac surgery. A good screening tool should be reproducible and user-independent, in addition to being highly sensitive. It is unclear, too, why nurse adherence to completing the 4AT assessment was so poor. One mentioned barrier to administration was that many patients seemed to still be quite sedated. We wonder whether some of these patients may have actually had unrecognized hypoactive delirium, which can be particularly difficult to detect. In any event, barriers to administration of this and other delirium screening tests should be investigated and addressed.
In summary, the authors investigated a highly relevant and important topic of postoperative delirium, which is common, under-recognized, and consequential. With more standardized methodology and incorporation of baseline and operative characteristics that may affect development of delirium, the utility of the 4AT in screening patients postcardiac surgery may be better understood.

\section{References}

1. Crocker E, Beggs T, Hassan A, Denault A, Lamarche Y, Bagshaw S, et al. Longterm effects of postoperative delirium in patients undergoing cardiac operation: a systematic review. Ann Thorac Surg. 2016;102:1391-9.

2. Seese L, Sultan I, Gleason TG, Navid F, Wang Y, Thoma F, et al. The impact of major postoperative complications on long-term survival after cardiac surgery. Ann Thorac Surg. 2020;110:128-35.

3. Hamadnalla H, Sessler DI, Troianos CA, Fang J, Rivas E, Ma C, et al. Optimal interval and duration of CAM-ICU assessments for delirium detection after cardiac surgery. J Clin Anesth. 2021;71:110233.

4. Tieges Z, Maclullich AMJ, Anand A, Brookes C, Cassarino M, O'connor M, et al Diagnostic accuracy of the 4AT for delirium detection in older adults: systematic review and meta-analysis. Age Ageing. 2021;50:733-43.

5. Chang Y, Ragheb S, Oravec N, Kent D, Nugent K, Cornick A, et al Diagnostic accuracy of the "4AT" delirium screening tool for the postoperative cardiac surgery ward. J Thorac Cardiovasc Surg. 2023;165: 1151-60.e8.

\title{
Commentary: The 4AT score- reducing confusion about delirium diagnosis after cardiac surgery
}

\author{
Ken K. S. Parhar, MD, MSc, ${ }^{\text {a,c }}$ and \\ Paul W. M. Fedak, MD, PhD, FRCS ${ }^{b, c}$
}

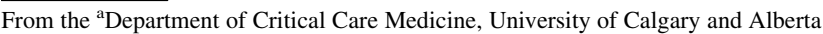
Health Services, Calgary, Alberta, Canada; 'bection of Cardiac Surgery, Department of Cardiac Sciences, Cumming School of Medicine, and ${ }^{c}$ Libin Cardiovascular Institute, University of Calgary, Calgary, Alberta, Canada.

Disclosures: The authors reported no conflicts of interest.

The Journal policy requires editors and reviewers to disclose conflicts of interest and to decline handling or reviewing manuscripts for which they may have a conflict of interest. The editors and reviewers of this article have no conflicts of interest.

Received for publication June 14, 2021; revisions received June 14, 2021; accepted for publication June 14, 2021; available ahead of print June 18, 2021.

Address for reprints: Paul W. M. Fedak, MD, PhD, FRCS, Section of Cardiac Surgery, Department of Cardiac Sciences, Cumming School of Medicine, University of Calgary, C849, 1403 29th St NW, Calgary, T2N 2T9 Alberta, Canada (E-mail: paul. fedak@gmail.com).

J Thorac Cardiovasc Surg 2023;165:1163-4

$0022-5223 / \$ 36.00$

Copyright (c) 2021 by The American Association for Thoracic Surgery

https://doi.org/10.1016/j.jtcvs.2021.06.023
}

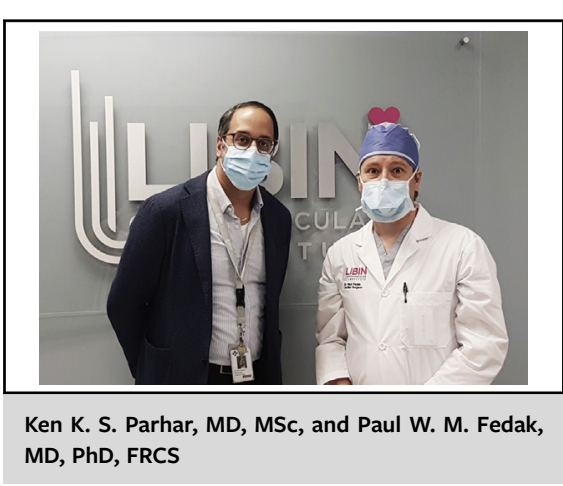

\section{CENTRAL MESSAGE \\ The $4 \mathrm{AT}$ score is a practical and accurate method to detect delirium in patients after cardiac surgery on the surgical ward and is administered effectively by nurses.}

Delirium remains one of the most common postoperative issues for patients after cardiac surgery. ${ }^{1}$ Patients 
postcardiotomy are at particular risk given their higher likelihood of atherosclerotic disease, exposure to cardiopulmonary bypass, and need for analgesia. ${ }^{1}$ It can be difficult to both diagnose and manage delirium. A missed diagnosis of delirium can lead to delays in recognizing primary underlying etiologies responsible for this syndrome, such as cerebrovascular accidents, nosocomial infections, and adverse drug effects. Ultimately, this results in increased morbidity, mortality, and hospital resource use. ${ }^{2}$ Delirium is distressing not only to care providers but also to patients' family members. ${ }^{3}$

Designing an assessment tool to detect delirium is not an easy task. Delirium is a fluctuating syndrome that can present in a hyperactive, hypoactive, or mixed form. Symptoms of inattention and cognitive dysfunction can be subtle. An optimal assessment tool must accurately detect delirium while being short, simple to learn, and easy to administer by the multidisciplinary team, and not requiring physical responses. Several tools to diagnose delirium exist; however, most of these tools have key disadvantages. ${ }^{4}$ Higher diagnostic sensitivity and specificity often result in a higher burden of work. Balancing the practicality of delirium screening with diagnostic accuracy is paramount. Organized methods to diagnose delirium using tools such as the Confusion Assessment Method (CAM) and Intensive Care Delirium Screening Checklist are helpful; however, they are limited by the time to administer, the effort for training, and the lack of validation outside of the intensive care setting. ${ }^{5}$ For both the CAM and Intensive Care Delirium Screening Checklist, limited validation exists in the cardiac surgery population.

In this issue of the Journal, Chang and colleagues ${ }^{6}$ assess and validate the use of the 4AT tool to diagnose delirium in patients after cardiac surgery. ${ }^{6}$ Using the 4AT tool provides several advantages. Importantly, it is short and simple, and requires little training to use. The diagnostic accuracy of the
4AT tool was evaluated in patients in the post-intensive care unit cardiac surgery ward, which is an area not well studied for delirium diagnosis. The results demonstrate that the 4AT score is more sensitive and specific than the CAM score at identifying delirium. Nurses could quickly implement the 4AT score with minimal training, showing improved feasibility compared with the CAM score. To accurately and efficiently detect delirium on a busy postoperative cardiac surgical ward is a noteworthy achievement.

Further work will be required to extend and validate these findings for other programs, given that this is a single-center study. Moreover, the frequency of optimal testing will need to be determined. The study by Chang and colleagues ${ }^{6}$ is an essential step in establishing a foundation to explore these questions. Achieving an accurate and pragmatic method of delirium detection, such as the 4AT score, is essential before we can effectively prevent and treat delirium for patients after cardiac surgery.

\section{References}

1. Chen H, Mo L, Hu H, Ou Y, Luo J. Risk factors of postoperative delirium after cardiac surgery: a meta-analysis. J Cardiothorac Surg. 2021;16:113.

2. Brown CH, Laflam A, Max L, Lymar D, Lymar D, Neufeld KJ, et al. The impact of delirium after cardiac surgical procedures on postoperative resource use. Ann Thorac Surg. 2016;101:1663-9.

3. Krewulak KD, Sept BG, Stelfox HT, Ely EW, Davidson JE, Ismail Z, et al. Feasibility and acceptability of family administration of delirium detection tools in the intensive care unit: a patient-oriented pilot study. CMAJ Open. 2019;7: E294-9.

4. Devlin JW, Skrobik Y, Gelinas C, Needham DM, Slooter AJC, Pandharipande PP, et al. Clinical practice guidelines for the prevention and management of pain, agitation/sedation, delirium, immobility, and sleep disruption in adult patients in the ICU. Crit Care Med. 2018;46:e825-73.

5. Gusmao-Flores D, Salluh JI, Chalhub RA, Quarantini LC. The confusion assessment method for the intensive care unit (CAM-ICU) and intensive care delirium screening checklist (ICDSC) for the diagnosis of delirium: a systematic review and meta-analysis of clinical studies. Crit Care. 2012;16: R115.

6. Chang Y, Ragheb S, Oravec N, Kent D, Nugent K, Cornick A, et al. Diagnostic accuracy of the "4 A's Test" delirium screening tool for the postoperative cardiac surgery ward. J Thorac Cardiovasc Surg. 2023;165:1151-60.e8. 